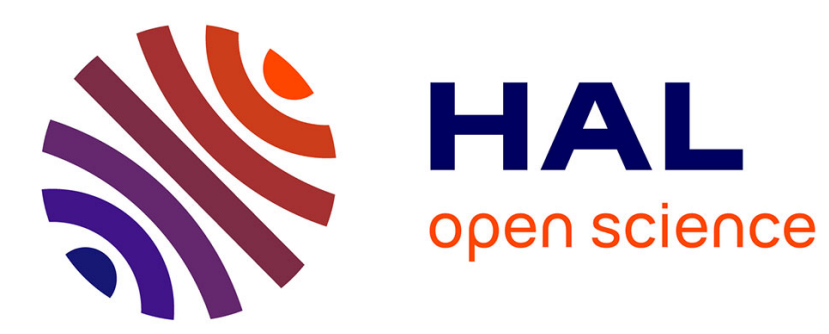

\title{
Modelling soil carbon dynamics with various cropping sequences on the rolling pampas
}

Adrian Andriulo, Bruno Mary, Jérôme Guerif

\section{To cite this version:}

Adrian Andriulo, Bruno Mary, Jérôme Guerif. Modelling soil carbon dynamics with various cropping sequences on the rolling pampas. Agronomie, 1999, 19 (5), pp.365-377. hal-00885937

\section{HAL Id: hal-00885937 \\ https://hal.science/hal-00885937}

Submitted on 1 Jan 1999

HAL is a multi-disciplinary open access archive for the deposit and dissemination of scientific research documents, whether they are published or not. The documents may come from teaching and research institutions in France or abroad, or from public or private research centers.
L'archive ouverte pluridisciplinaire HAL, est destinée au dépôt et à la diffusion de documents scientifiques de niveau recherche, publiés ou non, émanant des établissements d'enseignement et de recherche français ou étrangers, des laboratoires publics ou privés. 


\title{
Original article
}

\section{Modelling soil carbon dynamics with various cropping sequences on the rolling pampas}

\author{
Adrian Andriulo ${ }^{\mathrm{a}^{*}}$, Bruno Mary $^{\mathrm{b}}$, Jérôme Guerif ${ }^{\mathrm{b}}$ \\ a INTA, Estación Experimental de Pergamino, CC 31(2700), Pergamino, Argentina \\ b Inra. Unité d'Agronomie de Laon-Péronne, Rue Fernand Christ, 02007 Laon cedex, France
}

(Received 12 November 1998, accepted 9 March 1999)

\begin{abstract}
The two-compartment model of Hénin-Dupuis (1945) was tested to track the medium-term (13 years) evolution of $\mathrm{C}$ reserves in the silty soils of the rolling pampas in Argentina for various crop rotations. The coefficient of annual mineralisation, theoretically constant in the model, depends in fact on the amount of organic residues returned. The model is thus open to question. A simple model with three carbon fractions (harvest residues, active fraction and stable fraction) is proposed. It enables the changes in the soil organic reserves to be well simulated. However, a simple statistical fit of the three parameters of the model gives an infinite number of solutions. Use of the ${ }^{13} \mathrm{C}$ natural abundance method allows evolution of the young and old soil carbon fractions to be separated and tracked, and to determine the three parameters unambiguously. The results show that the stable fraction represents most of the initial soil organic $\mathrm{C}$ reserve: $60-68 \%$. The humification parameter increases in proportion to the lignin concentration of the crop residues. Intensification of soil tillage accelerates the mineralisation of the soil organic matter. (@) Inra/Elsevier, Paris.)
\end{abstract}

soil carbon / model / ${ }^{13} \mathrm{C}$ abundance / rolling pampas / cropping

Résumé - Modélisation des l'évolution des stocks de carbone des sols de la Pampa argentine pour différentes rotations culturales. Le modèle bicompartimental de Hénin-Dupuis (1945) a été évalué pour suivre l'évolution à moyen terme (13 ans) des stocks de $\mathrm{C}$ dans des sols limoneux de la Pampa ondulée en Argentine, pour diverses rotations de culture. Le coefficient de minéralisation annuel, théoriquement constant dans le modèle, dépend en fait du niveau des restitutions organiques. Le modèle est donc ainsi remis en cause. Un modèle simple à trois compartiments carbonés (résidus de récolte, fraction active et fraction stable) est proposé. Il permet de bien simuler l'évolution des stocks organiques du sol. Cependant, un simple ajustement statistique des trois paramètres du modèle donne une infinité de solutions. L'utilisation de la méthode d'abondance naturelle en ${ }^{13} \mathrm{C}$ permet de séparer et de suivre les évolutions de carbone jeune et du carbone ancien du sol, et de pouvoir déterminer les trois paramètres de façon univoque. Les résultats obtenus indiquent que la fraction stable représenterait la plus grande partie du stock de $C$ organique initial: 60 à $68 \%$. Le rendement d'humification augmente proportionnellement à la concentration en lignine des résidus de récolte. L'intensification du travail du sol induit une accélération de la minéralisation de la matière organique du sol. (ㅇ) Inra/Elsevier, Paris.)

carbone du sol / modélisation / abondance ${ }^{13} \mathrm{C}$ / pampa ondulée / mise en culture

Communicated by Mohamed Helal (Braunschweig, Germany)

* Correspondence and reprints

andriulo@inta.gov.ar 


\section{Introduction}

Several models have been proposed over the last 20 years to simulate the long-term dynamics of soil organic matter (SOM). These models use differing numbers of variables to describe the processes of SOM transformations [7, 18, 21, 23, 24, 26, 27]. They are conceptually interesting but difficult to validate and to apply as they require a large number of parameters which are difficult to measure. Hénin and Dupuis [14] were the first to simulate mathematically the evolution of soil organic matter with a simple model. In this model (figure 1) the SOM decomposes according to first order kinetics with a rate constant represented by the coefficient of mineralisation $k_{2}\left(\right.$ year $\left.^{-1}\right)$. This coefficient is assumed to be a characteristic of soil and climatic conditions. The model contains another parameter: the 'isohumic coefficient' $\left(k_{1}\right)$ which represents the yield of the transformation into humified carbon of the crop residues. It is a characteristic of the type of residues. This model has been used in numerous French studies to describe or predict the evolution of SOM reserves or of soil carbon $[9,13,25]$ and more recently by Huggins et al. [15]. However, Janssen [16] and Andrén and Kätterer [2] have suggested that one should consider at least two SOM fractions each with a specific turnover rate: a small labile fraction supplied from crop residues and a large, more stable, fraction of transformed 'humified' products. The use of such simulation models of the evolution of soil carbon reserves for the rolling pampas soils could be useful for predicting the consequences of different strategies for managing the organic matter in a region of relatively recent agriculture, where intensification is expected to alter the organic status of the soils.

The aim of this work is to simulate the evolution of the soil $\mathrm{C}$ reserves over the medium term observed in the rotation experiments carried out on the rolling pampas using the original two-compartment model of Hénin-Dupuis, and then a derived model with three compartments. The parameters can be estimated by fitting, meanwhile using the

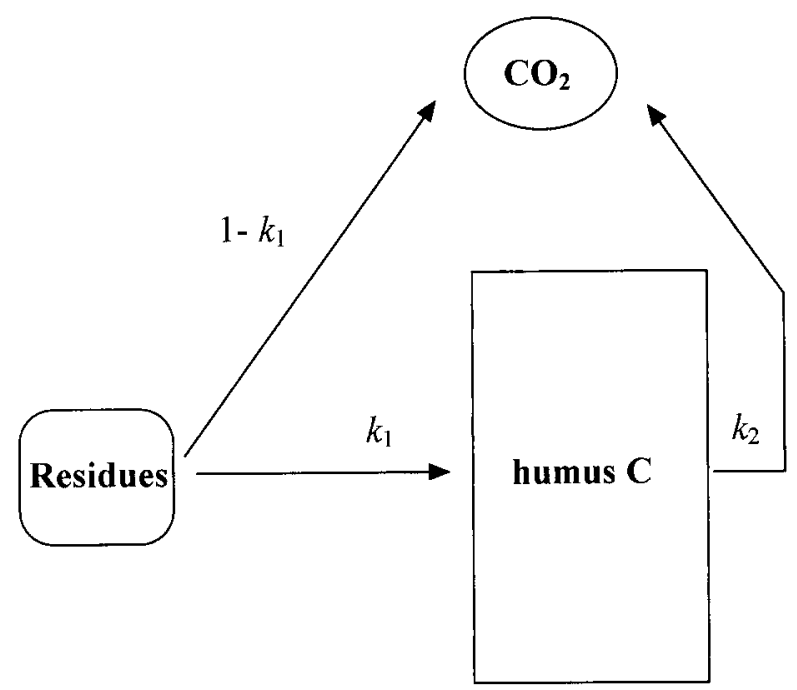

Figure 1. Diagram of Hénin-Dupuis' model considering two $\mathrm{C}$ pools. $k_{1}=$ humification rate of crop residues, $k_{2}=$ mineralisation rate of soil organic matter.

total $\mathrm{C}$ reserves and those of 'young C' calculated by the ${ }^{13} \mathrm{C}$ natural abundance method [5].

\section{Materials and methods}

\subsection{Experimental sites}

The data used in this work came from two mediumterm experiments carried out by INTA (Instituto Nacional de Tecnologia Agropecuaria). There was one crop rotation experiment carried out at the Oliveros Experimental Station $\left(33^{\circ} 01^{\prime} \mathrm{S}, 61^{\circ} 10^{\prime} \mathrm{W}\right)$ and another experiment with soybean monoculture carried out at the

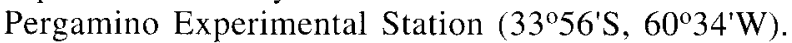
These two experiments were in the central part of the humid Argentinean pampas, in a natural sub-region known as the rolling pampas, the soils of which were developed on a thick loess (acquic and typic Argiudols, respectively). This work concerns the results of the first 13 years of both experiments. The experimental layouts have been described in detail by Andriulo et al. [5].

The treatments studied at Oliveros enable the transition from a mixed crop/livestock system lasting 60 years to a system of arable crops to be studied. The latter are as follows: 
w: continuous wheat;

m: continuous maize;

w/s: wheat/soybean, with two crops every year;

w/s-m: wheat/soybean-maize, with three crops every 2 years;

w/s-f: wheat/soybean-sunflower, with three crops every 2 years.

The study at Pergamino was concerned with the consequences of ploughing in the original grassland and the introduction of crops. The treatments were as follows:

p: original grassland;

s: continuous soybean.

\subsection{Two-compartment model}

The model of Hénin-Dupuis [14] considered two pools of OM: the OM in the crop residues and the humified SOM; the time step is the year. The annual variation of the humified SOM reserve can be written as:

$$
\Delta C / \Delta t=k_{1} m-k_{2} C
$$

where $C$ is the total humus carbon pool $\left(\mathrm{Mg}^{-h^{-1}}\right), m$ is the annual $\mathrm{C}$ application of crop residues $\left(\mathrm{Mg} \mathrm{ha}^{-1} \cdot \mathrm{year}^{-1}\right), k_{1}$ is the 'isohumic' coefficient representing the yield of the transformation into humified carbon of crop residues (unitless), $k_{2}$ is the mineralisation rate constant of the humified SOM (year-1).

If the residue returns can be considered constant over the integration interval, it becomes:

$$
C=C_{0} \cdot e^{-k_{2 t}}+\frac{m k_{1}}{k_{2}}\left(1-e^{-k_{2} t}\right)
$$

The longer the integration interval, the more the withinyear variability may be ignored, thus giving to $k_{1}$ and $k_{2}$ the meaning of mean annual coefficients. But the term $m$ depends on the crop and its yield and can take very different values. To improve the precision in estimating $k_{1}$ and $k_{2}$, we have had to take into account the variations in $m$. We have tested this model with the data from the rotation experiment at Oliveros. In these experiments, the initial $\mathrm{C}$ reserve $\left(C_{0}\right)$ is not known with great precision. Fitting the parameters of the model was performed in two stages.

- The first stage consists in making a simultaneous estimate of the three parameters $k_{1}, k_{2}$ and $C_{0}$ by the method of least squares, assuming (and fixing) known quantities of annual harvest residue returns $(m)$. This approach is similar to that used by Chadoeuf et al. [11] although these authors used a discrete formulation of the Hénin-Dupuisi model.

- The second stage is to test the sensitivity of the model to the parameter $k_{1}$ by giving it different values and optimising the parameter $k_{2}$. The coefficient $k_{1}$ is either fixed at 0.30 (the value used by Jenkinson [18]) or 1 (its maximum value), or otherwise calculated from the biochemical composition of the organic residues returned to the soil according to the formula proposed by Djakovitch [12]:

$$
\begin{gathered}
k_{1}=2.11-0.020 \mathrm{NDF} \\
-0.024 \mathrm{HEM}-0.022 \mathrm{CEL}+0.008 \mathrm{LIG}
\end{gathered}
$$

where NDF is the fraction of compounds soluble in neutral detergent ( $\%$ dry matter), HEM is the hemicellulose content (\%) and LIG the lignin content (\%).

The biochemical composition of each residue is shown in table III. The isohumic coefficient of each rotation is then calculated according to the following equations:

$k_{1}(w)=1.0 k_{1}($ wheat $)=0.11$

$k_{1}(\mathrm{~m})=0.7 k_{1}$ (maize) $+0.3 k_{1}$ (Sorghum halepense $)$ $=0.13$

$k_{1}(\mathrm{w} / \mathrm{s})=0.6 k_{1}($ wheat $)+0.4 k_{1}($ soybean $)=0.17$

$k_{1}(\mathrm{w} / \mathrm{s}-\mathrm{m})=0.2 k_{1}$ (wheat) $+0.2 k_{1}$ (soybean)

$+0.6 k_{1}($ maize $)=0.17$

$k_{1}(\mathrm{w} / \mathrm{s}-\mathrm{f})=0.3 k_{1}$ (wheat) $+0.2 k_{1}$ (soybean)

$+0.5 k_{1}$ (sunflower) $=0.26$

\subsection{Three-compartment model}

Hénin-Dupuis' model can be modified by separating the organic matter into a stable and an active fraction (figure 2). In this three-compartments model, the evolution of the carbon reserve may be described by the following equations:

$$
\begin{gathered}
C=C_{\hookleftarrow}+C_{\mathrm{A} 0} \cdot e^{-k t}+\frac{m k_{1}}{k} \cdot\left(1-e^{-k t}\right) \\
C_{0}=C_{\mathrm{S}}+C_{\mathrm{A} 0} \\
q=k_{1} \cdot m
\end{gathered}
$$

where $C_{s}$ is the stable $\mathrm{C}$ content $\left(\mathrm{Mg} \cdot \mathrm{ha}^{-1}\right), C_{\mathrm{A} 0}$ is the initial active $\mathrm{C}$ content $\left(\mathrm{Mg}^{-h a^{-1}}\right), C_{0}$ is the initial total $\mathrm{C}$ content $\left(\mathrm{Mg}^{-h^{-1}}\right), m$ is the mass of annual $\mathrm{C}$ input $\left(\mathrm{Mg} \mathrm{ha}^{-1}\right.$.year $\left.{ }^{-1}\right), k_{1}$ is the isohumic coefficient (unitless), $k$ is the coefficient of mineralisation of the active 


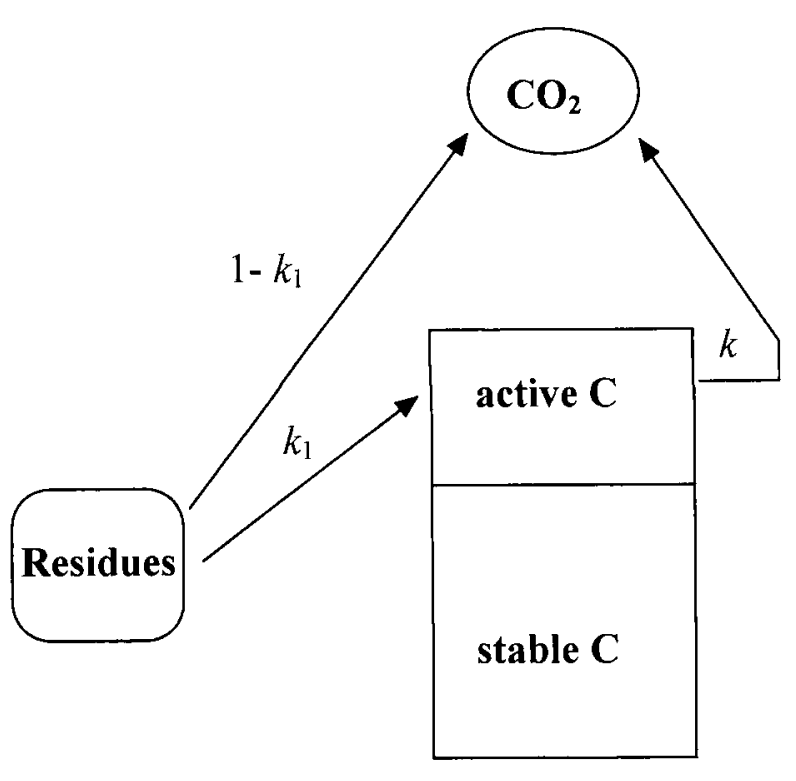

Figure 2. Diagram of the three-compartment model. $k_{1}=$ humification rate of crop residues, $k=$ mineralisation rate of active soil organic matter, $C_{\mathrm{S}}=$ stable $\mathrm{C}$ fraction.

fraction $\left(\right.$ year $\left.^{-1}\right), q$ is the mass of $\mathrm{C}$ humified annually $\left(\mathrm{Mg} \mathrm{ha}^{-1}\right.$.year $\left.{ }^{-1}\right)$.

\subsection{Calculation of active and stable carbon reserves using ${ }^{13} \mathrm{C}$ measurements}

In the previous paragraph we estimated the size of the compartments and their evolution by statistical fitting. We have improved their estimates by using measurements of natural ${ }^{13} \mathrm{C}$ isotopic abundance. We continue to use the three-compartment model (the modified Hénin-Dupuis model) but will consider the changes in 'young' and 'old' carbon separately.

Equation (4) of the three-compartment model can in fact be written:

$$
C=C_{1}+C_{2}
$$

with

$$
C_{1}=C_{\mathrm{S}}+C_{\mathrm{A} 0} \cdot e^{-k t}
$$

and

$$
C_{2}=\frac{m k_{1}}{k} \cdot\left(1-e^{-k t}\right)
$$

The term $C_{1}(t)$ describes the evolution (decrease) of the $\mathrm{C}$ content present at time 0 : we call it 'old C', since it includes the stable carbon pool $C_{\mathrm{S}}$. The term $C_{2}(t)$ represents the 'young $C$ ', i.e. the amount of active carbon formed since time 0 .

The equations can also be written in the form:

$$
C_{1}=C_{\mathrm{S}}+\left(C_{0}-C_{\mathrm{S}}\right) \cdot e^{-k r}
$$

and

$$
C_{2}=C_{\max } \cdot\left(1-e^{-k i}\right)
$$

$C_{0}$ being the total quantity of soil carbon at time 0 , and $C_{\max }$ the maximum contribution of the rotation to the young carbon pool at equilibrium

$$
\begin{gathered}
C_{\max }=\frac{k_{1} m}{k} \\
C_{\mathrm{eq}}=C_{\max }+C_{\mathrm{S}}
\end{gathered}
$$

$C_{\mathrm{eq}}$ being the total quantity of soil carbon at equilibrium. We have simulated the evolution of young and old carbon in five of the rotations studied at Oliveros, with the exception of the wheat/soybean-maize rotation. In fact it is difficult to estimate the $\delta^{13} \mathrm{C}$ contributions from this rotation which was made up of a mixture of species with $\mathrm{C} 3$ (wheat and soybean) and $\mathrm{C} 4$ (maize) photosynthetic cycles. In the other rotations, the $\delta^{13} \mathrm{C}$ measurements allow the proportion of young carbon in the soil at time $t$ compared with the total carbon to be calculated. We recall the formula for calculating this proportion $\alpha$ :

$$
\alpha=\frac{\delta_{\mathrm{m}}-\delta_{1}}{\delta_{2}-\delta_{1}}
$$

where $\delta_{u}$ is the isotopic abundance of ${ }^{13} \mathrm{C}$ in the soil at time $t(\%), \delta_{l}$ is the isotopic abundance of ${ }^{13} \mathrm{C}$ in the soil at time $t=0(\%)$ and $\delta_{2}$ is the isotopic abundance of ${ }^{13} \mathrm{C}$ of the crops in the rotation $(\%)$.

When $\alpha$ is known, the young and old carbon contents can be calculated:

$$
\begin{aligned}
& \text { young } \mathrm{C}: C_{2}=\alpha \cdot C_{\mathrm{S}} \\
& \text { old C: } C_{1}=(1-\alpha) \cdot C
\end{aligned}
$$

We have tried to fit the two models at the same time, i.e. by minimising the sums of squares of deviations from the model for the variables $C_{1}$ and $C_{2}$. Whilst optimising, we have taken account of the variance of the data by weighting the sums of squares of deviations. The following quantity was minimised:

$$
S S Q=\frac{S S Q_{1}}{s_{1}^{2}}+\frac{S S Q_{2}}{S_{2}^{2}}
$$


where $S S Q_{1}$ and $S S Q_{2}$ are the sums of squares of deviations (observed - simulated) of the variables $C_{1}$ and $C_{2}$, respectively; $s_{1}^{2}$ and $s_{2}^{2}$ are the mean experimental variances obtained for the variables $C_{1}$ and $C_{2}$. Fitting was performed in two different ways.

a) By fixing $C_{0}$ and $m$. In this case three parameters are optimised: $C_{\mathrm{S}}, k_{1}$ and $k_{2}$.

b) By fixing $C_{0}$ and $C_{\mathrm{S}}$. In this case two parameters are optimised: $k_{1}$ and $k$.

To judge the goodness of fit, we have used the following two complementary criteria.

- The residual mean square error (RMSE) which defines the mean difference between observed $\left(C_{i}\right)$ and simulated $\hat{C}_{i}$ values:

$$
R M S E=\frac{\sqrt{\bar{\Sigma}\left(\hat{C}_{i}-C_{i}\right)^{2}}}{n-p}
$$

where $p$ is the number of fitted parameters.

- The lack of fit (LOFIT) which separates the sum of squares of differences between measurements and simulation into two components: one is calculated as the difference between the simulation and the mean of repeated measurements ('lack of fit') and the other is calculated from the variance of each set of repeated measurements ('the pure error'). The statistical significance of the systematic errors (LOFIT) can be calculated using an $F$ test [28]:

$$
F=\frac{M S L O F I T}{M S E}=\frac{\sum_{j=1}^{N}\left(m_{j}-1\right) \sum_{j=1}^{N} m_{j}\left(\bar{O}_{j}-P_{j}\right)^{2}}{N \sum_{j=1} N \sum_{i=1}^{N}\left(\left(O_{i j}-P_{j}\right)-\left(\bar{O}_{j}-P_{j}\right)\right)^{2}}
$$

If the calculated $F$ is significantly greater than a critical $F(P<0.05)$ the model is inadequate.

\section{Results and discussion}

\subsection{Description of the kinetics according to the Hénin-Dupuis model}

The Hénin-Dupuis model was tested on the results of the Oliveros experiment which compared five rotations over 13 years. Only the parameters $k_{1}$ and $k_{2}$ were fitted, as the initial reserves and amounts of organic residues returned were well known.
The results of fitting without constraints are quite good as the RMSE varies between 0.4 and 1.2 $\mathrm{Mg} \mathrm{C} \cdot \mathrm{ha}^{-1}$ and the LOFIT is not significant (results not shown). But this optimisation always leads to unrealistic values of $k_{1}$, i.e. greater than 1 . We have therefore carried out a sensitivity analysis on the parameter $k_{1}$. It should be noted that the coefficient $k_{\mathrm{I}}$ is either fixed at 0.30 (the value used by Jenkinson [18]) or 1 (the maximum value) or calculated from the biochemical composition using the formula suggested by Djakovitch [12].

Table I gives the results from fitting after having fixed the parameter $k_{1}$ (only $k_{2}$ is optimised). A significant decrease in the quality of fit was found for all the rotations: a large increase in RMSE when $k_{1}$ is fixed and LOFIT significant in one rotation. The model fits the data better with values of $k_{1}$ close to 1 than when using the value calculated from Djakovitch's formula: this is true for four of the five rotations. The wheat/soybean rotation shows the worst fit: $\mathrm{RMSE}=1.8 \mathrm{Mg} \mathrm{C} \cdot \mathrm{ha}^{-1}$.

Table I. Prediction of the mineralisation rate $\left(k_{2}\right)$ of SOM by the Hénin-Dupuis' model as dependent on annual $\mathrm{C}$ input $(\mathrm{m})$ and humification coefficient $\left(k_{1}\right)$ under various crop rotations at Oliveros.

\begin{tabular}{lccccc}
\hline $\begin{array}{l}\text { Crop } \\
\text { sequence }\end{array}$ & $\begin{array}{c}m \\
\left(\mathrm{Mg.ha}^{-1}\right. \\
\left.\text { year }^{-1}\right)\end{array}$ & $k_{1}$ & $\begin{array}{c}k_{2} \\
\left(\text { year }^{-1}\right)\end{array}$ & $\begin{array}{c}\text { RMSE } \\
\left(\mathrm{Mg.ha}^{-1}\right)\end{array}$ & LOFIT \\
w & 2.9 & 0.11 & 0.022 & 1.4 & NS \\
& & 0.30 & 0.039 & 1.3 & NS \\
& & 1.00 & 0.101 & 1.1 & NS \\
m & 4.5 & 0.13 & 0.030 & 1.4 & NS \\
& & 0.30 & 0.054 & 1.3 & NS \\
& & 1.00 & 0.150 & 0.8 & NS \\
w/s & 5.0 & 0.17 & 0.036 & 1.8 & NS \\
& & 0.30 & 0.056 & 1.7 & NS \\
& & 1.00 & 0.160 & 1.4 & NS \\
w/s-f & 3.4 & 0.26 & 0.036 & 1.7 & S \\
& & 0.30 & 0.040 & 1.6 & S \\
& & 1.00 & 0.110 & 1.4 & NS \\
w/s-m & 3.8 & 0.17 & 0.033 & 1.2 & NS \\
& & 0.30 & 0.048 & 1.1 & NS \\
& & 1.00 & 0.130 & 0.8 & NS \\
\hline
\end{tabular}

Three possible values are given for the $k_{1}$ parameter (see text). Initial soil C content: $C_{0}=35.2 \mathrm{Mg} \cdot \mathrm{ha}^{-1}$. 
If the 'biochemical value' defined by equation (3) is used for $k_{1}$, the calculated values of $k_{2}$ for the five rotations lie between 0.022 and 0.036 year $^{-1}$. These value hardly differ from those obtained when $k_{1}$ is fixed at 0.15 .

\subsection{Limitations of the two-compartment model}

The deviations from the model remain comparable with the error measurements of the $C$ reserves (at least for three rotations) and do not allow the two-compartments model to be rejected directly. Nevertheless the model is not satisfactory because, on the one hand, the simultaneous estimation of the model parameters does not lead to consistent values of $k_{1}$, and on the other hand the independent estimate of $k_{2}$ fails to solve the problem of systematic bias: the model under-estimates the initial fall in $\mathrm{C}$ content in the first years, and over-estimates it later on. These conclusions confirm those of other authors $[9,22,25]$. If one chooses to fix $k_{1}$, one risks making a serious mistake by assuming that all the harvest residues have the same humification yield. In fact this hypothesis is too simple: it is probable that $k_{1}$ is a characteristic of the composition of the organic residues. Moreover, the increase in the amount of carbon applied to the soil each year results in an increase in the mineralisation rate (figure 3). This observation is true whichever value of the coefficient $k_{1}$ is used, and thus does not result from the correlation which exists between $k_{1}$ and $k_{2}$ in the fitting procedure. Thus, as $k_{2}$ loses its status as a constant, the two-compartment model becomes inadequate.

\subsection{Description of the kinetics using the three-compartment model}

The three-compartment model was therefore tested at Oliveros. The calculation of the three parameters of the model $\left(C_{S}, k_{1}\right.$ and $k$ ) by fitting to the data from the five rotations revealed a very strong correlation between the parameters $C_{\mathrm{S}}$ and $k_{1}$. This means we must fit the values of $k$ and $C_{\mathrm{S}}$ after having fixed the coefficient $k_{1}$ at 0.15 or 0.30 .

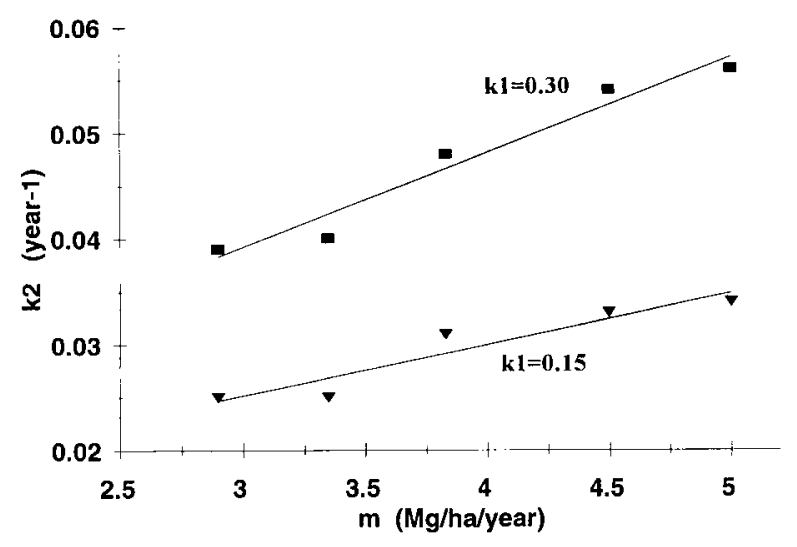

Figure 3. Variation of the mineralisation rate $(k$,$) of soil$ organic matter in the Hénin-Dupuis' model as a function of annual $\mathrm{C}$ inputs.

The results obtained with these two values of $k_{l}$ generally show a good fit of the model to the observed data for total $\mathrm{C}$ contents in the plough layer (table $I I$ ). The statistical criteria for fitting are satisfactory: the RMSE varies from 0.31 to 1.34 $\mathrm{Mg} \mathrm{C} \cdot \mathrm{ha}^{-1}$, the variance accounted for $\left(\mathrm{r}^{2}\right)$ varies from 0.61 to 0.97 and the LOFIT is not significant for any rotation.

The values of $k$, calculated for each rotation, are independent of the value of $k_{1}$ chosen. It is also found that the value of the parameter $C_{S}$, calculated without constraints, varies little between rotations. The mean value obtained in these fittings is $C_{\mathrm{S}}=27.6 \mathrm{Mg} \cdot \mathrm{ha}^{-1}$. As expected, it will be assumed that the stable carbon fraction is constant and independent of the rotation. This value was used from then on without resulting in either a observable increase in RMSE or in a significant LOFIT (table II).

Depending on the rotation, the calculated values of $k$ varied from 0.16 (wheat monoculture) to 0.56 year $^{-1}$ (wheat/soybean rotation). The comparison of rotations suggests that the mineralisation rate $k$ depends on the amount of $\mathrm{C}$ input (the higher the input, the greater the mineralisation of SOM) and the soil tillage (ploughing seems to increase the mineralisation rate). 
Table II. Values of model parameters $\left(k_{1}, C_{\mathrm{S}}\right.$ and $\left.k\right)$ and quality of fit obtained with the three-compartment model in the Oliveros experiment.

\begin{tabular}{|c|c|c|c|c|c|c|}
\hline Crop sequence & $k_{1}$ & $\begin{array}{c}\text { Parameters } \\
C_{\mathrm{S}} \\
\left(\mathrm{Mg}^{-h^{-1}}\right)\end{array}$ & $\begin{array}{c}k \\
\text { year }^{-1}\end{array}$ & 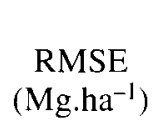 & $\begin{array}{l}\text { Quality of fit } \\
r^{2}\end{array}$ & LOFIT \\
\hline w & $0.15^{*}$ & 27.2 & 0.16 & 1.04 & 0.84 & NS \\
\hline $\mathrm{m}$ & $0.15^{*}$ & 28.3 & 0.29 & 0.48 & 0.97 & NS \\
\hline $\mathrm{w} / \mathrm{s}$ & $0.15^{*}$ & 30.3 & 0.56 & 0.31 & 0.97 & NS \\
\hline $\mathrm{w} / \mathrm{s}-\mathrm{f}$ & $0.15^{*}$ & 29.5 & 0.23 & 1.34 & 0.61 & NS \\
\hline $\mathrm{w} / \mathrm{s}-\mathrm{m}$ & $0.15 *$ & 28.2 & 0.24 & 0.63 & 0.90 & NS \\
\hline w & $0.30^{*}$ & 24.5 & 0.16 & 1.04 & 0.84 & NS \\
\hline $\mathrm{m}$ & $0.30^{*}$ & 25.9 & 0.29 & 0.48 & 0.97 & NS \\
\hline $\mathrm{w} / \mathrm{s}$ & $0.30 *$ & 29.0 & 0.56 & 0.31 & 0.97 & NS \\
\hline$w / s-f$ & $0.30^{*}$ & 27.3 & 0.23 & 1.34 & 0.61 & NS \\
\hline $\mathrm{w} / \mathrm{s}-\mathrm{m}$ & $0.30 *$ & 25.8 & 0.24 & 0.63 & 0.90 & NS \\
\hline w & 0.13 & $27.6^{*}$ & 0.16 & 1.04 & 0.84 & NS \\
\hline $\mathrm{m}$ & 0.19 & $27.6^{*}$ & 0.29 & 0.48 & 0.97 & NS \\
\hline $\mathrm{w} / \mathrm{s}$ & 0.46 & $27.6^{*}$ & 0.56 & 0.31 & 0.97 & NS \\
\hline $\mathrm{w} / \mathrm{s}-\mathrm{f}$ & 0.28 & $27.6^{*}$ & 0.23 & 1.34 & 0.61 & NS \\
\hline $\mathrm{w} / \mathrm{s}-\mathrm{m}$ & 0.19 & $27.6^{*}$ & 0.24 & 0.63 & 0.90 & NS \\
\hline
\end{tabular}

The fitted data include only total soil C contents. * Fixed parameter (the other two parameters are fitted).

\subsection{Calculation of active and stable carbon reserves using ${ }^{13} \mathrm{C}$ measurements}

In the previous paragraph we estimated the sizes of the compartments and their evolution by statistical fitting. We can now improve these estimates by making use of measurements of ${ }^{13} \mathrm{C}$ natural isotopic abundance. We will still use the three-compartment model (the modified Hénin-Dupuis model) but will consider the 'young carbon' and the 'old carbon' separately in the Oliveros and Pergamino experiments.

\subsubsection{Oliveros experiment}

\subsubsection{Fitting the model parameters}

We have simulated the evolution of young and old carbon in four rotations at Oliveros. Fitting was performed in the following two different ways.

a) By fixing $C_{0}$ and $m$ (table IIla). In this case three parameters are optimised: $C_{\mathrm{S}}, k_{1}$ and $k$. b) By fixing $C_{0}, m$ and $C_{\mathrm{S}}$ (table $\left.I I I b\right)$. In this case two parameters are optimised: $k_{1}$ and $k$.

The statistical criteria show that the quality of fit is very good. The calculated values of the stable $\mathrm{C}$ pool hardly differ between rotations, except for the maize monoculture. We then assumed that the stable carbon pool was the same in all treatments, which means that the possible effect of the rotation on the stable carbon is negligible over such a short period (13 years). We have therefore adopted for stable $C$ the value $C_{\mathrm{S}}=23.7 \mathrm{Mg} \cdot \mathrm{ha}^{-1}$, which is the value which minimises the sum of squares of deviations, weighted by the variance, in the four rotations.

When the parameter $C_{\mathrm{S}}$ is fixed and the two parameters $k_{1}$ and $k$ are optimised, only a small fall is seen in the quality of fit: the RMSE increases, but remains lower than the RMSE of the fits previously carried out, and the model is still without bias (LOFIT is not significant) (table IIIb). 
Table III. Values of model parameters $\left(k_{l}, C_{S}\right.$ and $\left.k\right)$ and quality of fit obtained with the three-compartment model in the Oliveros experiment.

\begin{tabular}{|c|c|c|c|c|c|c|}
\hline Crop sequence & $\begin{array}{c}C_{\mathrm{s}} \\
\left(\mathrm{Mg} \cdot \mathrm{ha}^{-1}\right)\end{array}$ & $\begin{array}{c}\text { Parameters } \\
k \\
\left(\text { year }^{-1}\right)\end{array}$ & $k_{1}$ & $\begin{array}{c}\text { RMSE } \\
\left({\left.\mathrm{Mg} . h a^{-1}\right)}^{-}\right.\end{array}$ & Quality of fit & LOFIT \\
\hline \multicolumn{7}{|c|}{ a) $m$ and $C_{0}$ fixed } \\
\hline $\mathrm{w}$ & 27.0 & 0.33 & 0.47 & 0.34 & 0.999 & NS \\
\hline $\mathrm{m}$ & 14.2 & 0.08 & 0.23 & 0.38 & 0.995 & NS \\
\hline$w / s$ & 24.0 & 0.32 & 0.47 & 0.14 & 0.999 & NS \\
\hline$w / s-f$ & 24.6 & 0.27 & 0.58 & 0.32 & 0.998 & NS \\
\hline \multicolumn{7}{|c|}{ b) $m, C_{0}$ and $C_{\mathrm{S}}$ fixed } \\
\hline $\mathrm{W}$ & 23.7 & 0.16 & 0.29 & 0.76 & 0.997 & NS \\
\hline $\mathrm{m}$ & 23.7 & 0.21 & 0.35 & 0.86 & 0.977 & NS \\
\hline $\mathrm{w} / \mathrm{s}$ & 23.7 & 0.31 & 0.45 & 0.29 & 0.999 & NS \\
\hline$w / s-f$ & 23.7 & 0.24 & 0.53 & 0.40 & 0.998 & NS \\
\hline
\end{tabular}

The fitted data include both total soil $\mathrm{C}$ and natural ${ }^{13} \mathrm{C}$ abundance data. (a) $m$ and $C_{\theta}$ are fixed; $C_{S}, k$ and $k$, are fitted. (b) $m, C_{o}$ and $C_{S}$ are fixed; $k$ and $k_{l}$ are fitted.

The evolution of young and old carbon reserves is still very well simulated in every case (figure 4). A slight bias can only be seen in the case of maize monoculture: the model over-estimates the first measurement of young carbon at 4 years.

A reserve of stable $\mathrm{C}$ of $23.7 \mathrm{Mg} \cdot \mathrm{ha}^{-1}$ (corresponding to a $\mathrm{C}$ content of $12-13 \mathrm{mg} \cdot \mathrm{g}^{-1}$ soil) would therefore be associated with an active $\mathrm{C}$ reserve of $11.5 \mathrm{Mg} \cdot \mathrm{ha}^{-1}$ at the start of the experiment. At the beginning of the study, the active fraction would thus have represented $1 / 3$ of the total $C$ reserve of the plough layer. This proportion is similar to that calculated by Mary and Guérif [20] for the Rothamsted plots. These authors predicted that for the treatment without fertiliser, and when equilibrium was reached, the active fraction would represent $19 \%$ of the total organic matter. In our case the active fraction would represent, at equilibrium, about $22 \%$ of the total $\mathrm{C}$.

\subsubsection{Values of the rate constant $k$}

The rate constant of mineralisation $k$ varies with the rotation from 0.16 to 0.31 year $^{-1}$ (table IIIb). These values are high, indicating that the transition to a new equilibrium state is quick: the half-life of the active fraction being from 2.5 to 4 years.
The rate constant of mineralisation $k$ of the three-compartment model may be compared with the constant $k_{2}$ of the two-compartment model using the following relation:

$$
k_{2} \approx k \cdot \frac{C_{\mathrm{A}}}{C_{\mathrm{A}}+C_{\mathrm{S}}}
$$

Using the values of $k$ from table IIIb and for different values of the carbon content in the compartments, the values of $k_{2}$ obtained fall between 0.04 and 0.10 year $^{-1}$ which are in agreement with values in the literature, bearing in mind the climatic characteristics of our study region.

Analysis of the cultural operations of each rotation shows that there is a positive correlation between the mineralisation rate and the number of annual tillage operations (figure 5). It is also possible that the main ploughing date might play a role: ploughing is carried out in autumn for wheat, maize and sunflower; it is carried out in a warmer period (December) in the case of soybean, which might stimulate SOM mineralisation more.

\subsubsection{Values of $k_{1}$}

The values of $k_{1}$ found vary between 0.29 and 0.53 (table III b). These values, which represent the 

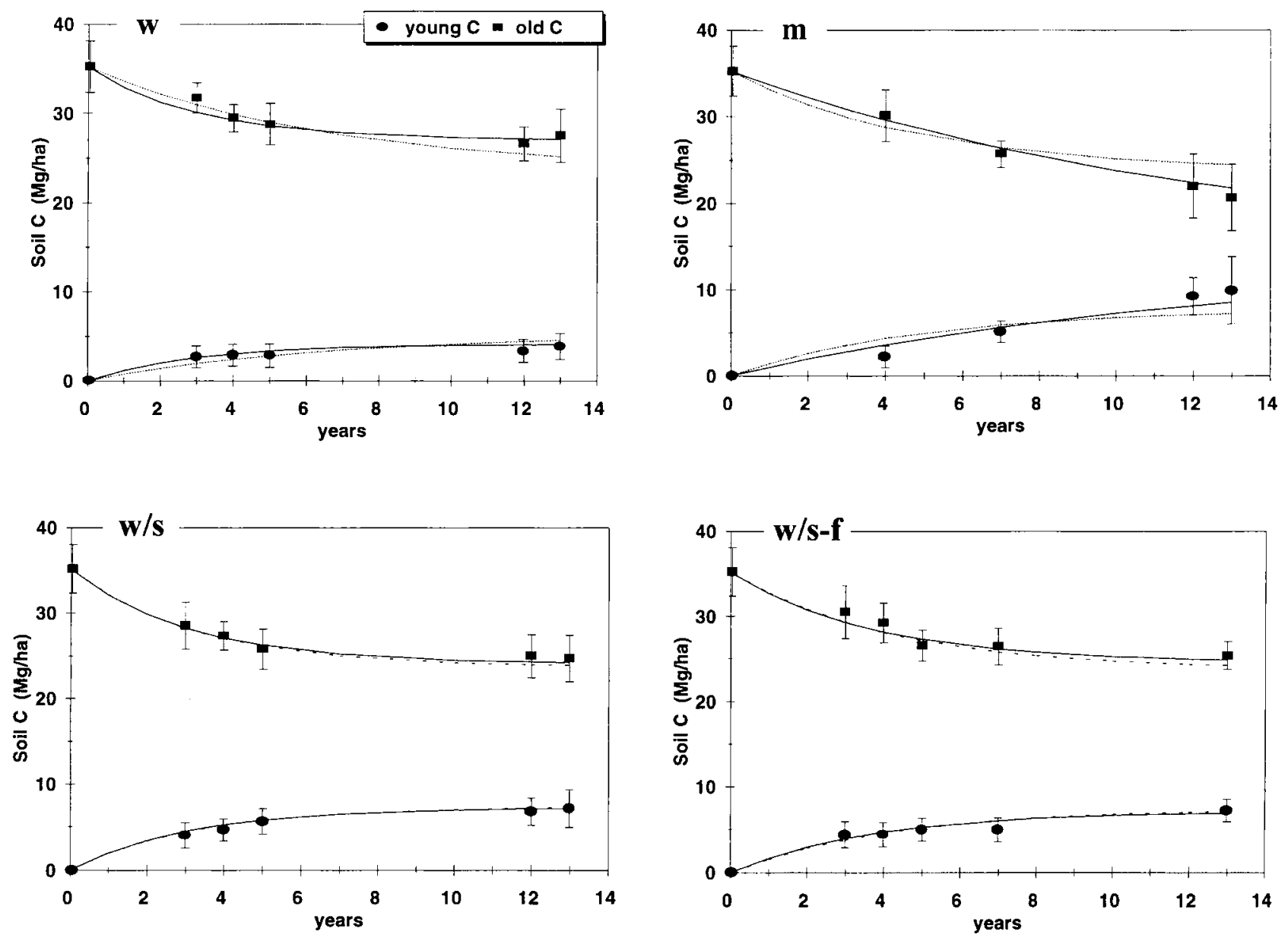

Figure 4. Evolution of predicted (lines) and observed values (points) of old and young $C$ fractions of SOM under four cropping sequences at Oliveros. Full lines: $m$ and $C_{0}$ fixed. Dashed lines: $m, C_{0}$ and $C_{S}$ fixed.

humification yield of the $\mathrm{C}$ from the crop residues which are incorporated into the soil, are not well reported in the international literature. The values normally used for straw cereals are between 0.06 and 0.30 for the aerial parts and between 0.16 and 0.30 for the below-ground parts.

In our study, we found values higher than those currently assumed. If we wanted to obtain a value for $k_{1}$ of 0.15 , frequently used in France, the amounts of $\mathrm{C}$ applied in each rotation would have to be $5.7,10,15$ and $12 \mathrm{Mg} \cdot \mathrm{ha}^{-1}$.year ${ }^{-1}$ for the $\mathrm{w}$, $\mathrm{m}, \mathrm{w} / \mathrm{s}$ and $\mathrm{w} / \mathrm{s}-\mathrm{f}$ rotations, respectively. These values are unlikely even if the residue returns were considerably under-estimated. Our results agree with those of Jenkinson [18] who adopted the value $k_{1}=0.30$ and obtained a good simulation of the long-term Rothamsted experiments; HéninDupuis [14] and Janssen [16] also used higher values for crop residues: $k_{1}=0.40$. The value of $k_{1}$ can also be compared with the coefficient $\alpha+\beta$ in the model of Bradbury et al. [10] which, according to these authors, varies between 0.35 and 0.42 .

Figure 6 shows that the values of $k_{1}$ calculated by fitting are well correlated with the lignin content of the residues applied in each rotation. The linear regression obtained is 


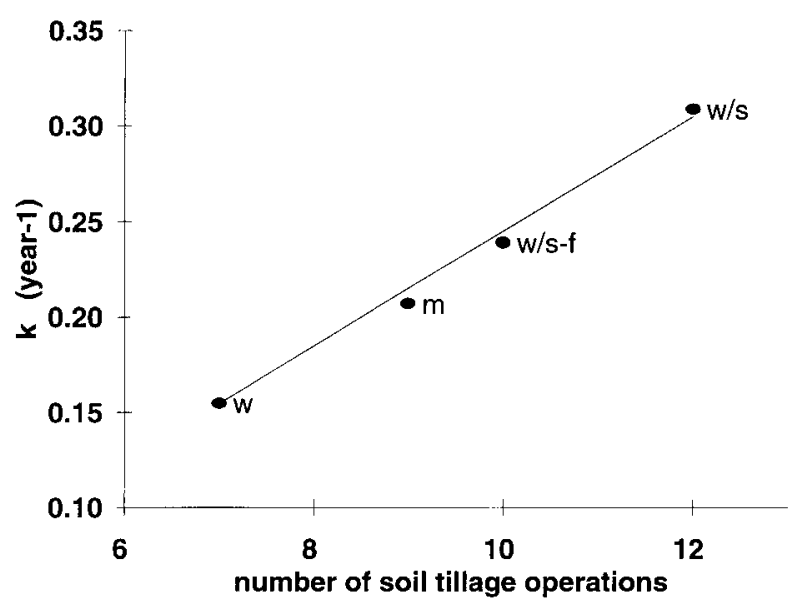

Figure 5. Mineralisation rate of active organic matter $(k)$ as dependent on the number of tillage operations performed each year at Oliveros.

$$
\mathrm{k}_{1}=-0.302+0.084 \mathrm{LIG}
$$

\subsubsection{Testing the model}

The validity of the model thus parameterised $\left(C_{\mathrm{S}}, k_{1}, k\right)$ could be tested on the w/s-m rotation, which we had abandoned because it did not enable us to calculate the young and old $\mathrm{C}$. The simulation of the evolution of the total $\mathrm{C}$ content was carried out year by year, taking into account the residue returns of wheat, soybean and maize. It appeared to be capable of reproducing the observed evolution in this rotation over the course of the 13 years of the study (figure 7). The $\mathrm{C}$ reserve at equilibrium, calculated at $30.5 \mathrm{Mg} \cdot \mathrm{ha}^{-1}$, would be almost reached by the end of the 13 years.

\subsubsection{Carbon content at equilibrium}

The model indicates that the $\mathrm{C}$ content at equilibrium (equation (13)) would vary little although the quantity $q$ of carbon humified annually (equation (6)) differs greatly from one rotation to another (table $I V$ ). Thus, the humified carbon applications from the wheat monoculture are limited both by relatively small amounts returned and by a low lignin content $(7.5 \%)$. The $\mathrm{C}$ inputs in the $\mathrm{w} / \mathrm{s}$ rotation, made up of residues from two crops in the same year, are particularly high; this effect is supported by the lignin content of soybean $(10.6 \%)$.

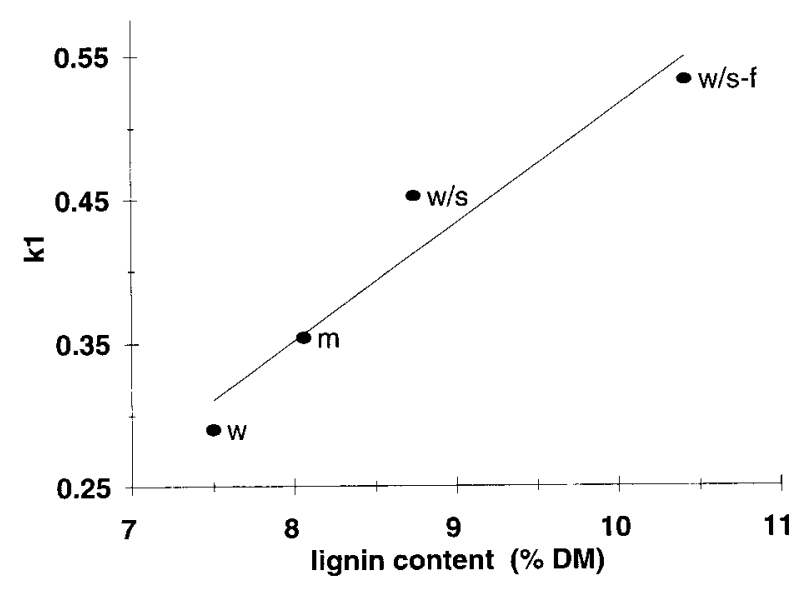

Figure 6. Humification rate of different crop residues $\left(k_{l}\right)$ versus their lignin content at Oliveros.

Table IV. Measured annual $C$ inputs $(q)$, amounts of young $\mathrm{C}\left(C_{\max }\right)$ and total $\mathrm{C}\left(C_{\mathrm{eq}}\right)$ predicted at equilibrium level.

\begin{tabular}{|c|c|c|c|}
\hline $\begin{array}{l}\text { Crop } \\
\text { sequence }\end{array}$ & $\begin{array}{c}q \\
\left.a^{-1} \cdot \text { year }^{-1}\right)\end{array}$ & $\begin{array}{c}C_{\max } \\
\left(\mathrm{Mg} \cdot \mathrm{ha}^{-1}\right)\end{array}$ & $\begin{array}{c}C_{\mathrm{eq}} \\
\left(\mathrm{Mg}_{\mathrm{ha}} \mathrm{a}^{-1}\right)\end{array}$ \\
\hline Wheat & 0.8 & 5.2 & 28.9 \\
\hline Maize & 1.6 & 7.7 & 31.4 \\
\hline $\begin{array}{l}\text { Wheat/soybean } \\
\text { Wheat/ }\end{array}$ & 2.3 & 7.3 & 31.0 \\
\hline Soybean-sunflower & 1.8 & 7.5 & 31.2 \\
\hline
\end{tabular}

Initial value: $\delta^{13} \mathrm{C}_{0}=-17.4 \%$.

The contribution of sunflower in the $\mathrm{w} / \mathrm{s}-\mathrm{f}$ rotation is linked to its high lignin content $(12.1 \%)$. On the other hand, the low lignin content of the maize-Sorghum halepense combination $(8.1 \%)$ limits the effect of the large mass of harvest residues applied. Moreover, it appears that, except for wheat, the young carbon content at equilibrium $C_{\max }$ (equation (12)) does not depend on the rotation. It is thus the variation in the rate of soil carbon mineralisation between rotations which limits the variations in reserves which might be induced by the different residue returns. 


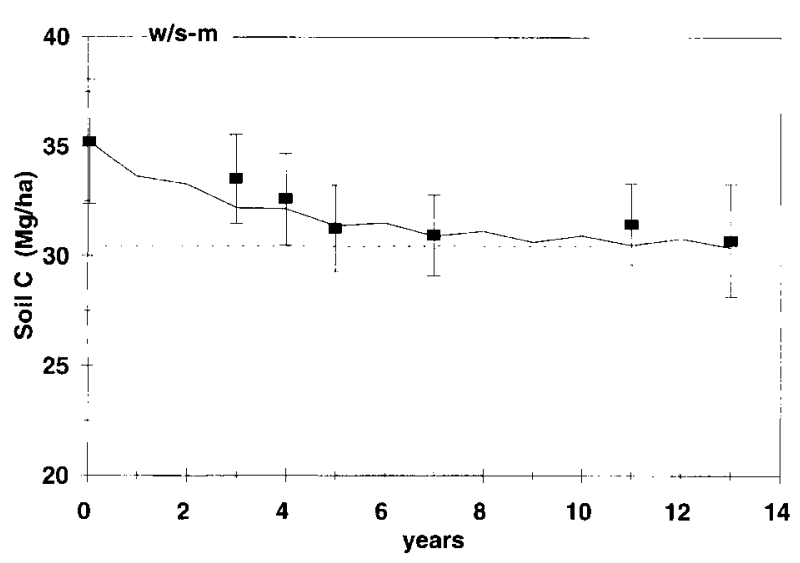

Figure 7. Evolution of predicted and observed soil C content under the rotation wheat/soybean-maize at Oliveros. The predicted values are calculated from the effective amounts of crop residues, the stable carbon pool $C_{S}=23.7 \mathrm{Mg} \cdot \mathrm{ha}^{-1}$, the $k$ and $k_{\text {I }}$ coefficients corresponding to figures 5 and 6 .

From a practical point of view, if the increase in mineralisation is indeed due to soil tillage, the organic matter reserves at equilibrium could be increased by limiting the number of cultural operations, for example by leaving out the ploughing before the soybean crop.

\subsubsection{The Pergamino experiment (soybean monoculture)}

For the Pergamino experiment, we proceeded as before by simultaneously fitting both equations representing the evolution of young and old $\mathrm{C}$ ( figure 8 ). The results obtained gave a high value of the decomposition rate: $k=0.31$ year $^{-1}$. This confirmed that the introduction of crops into the rolling Argentinean pampas brings about a very rapid change in the organic reserve towards a new equilibrium (half-life $=2$ years). Our earlier studies [5] have shown that the fall in $\mathrm{C}$ content is not due to the fall in $\mathrm{C}$ applications. Thus, we find that the values of $C_{\max }$ and $q, 6.9 \mathrm{Mg} \cdot \mathrm{ha}^{-1}$ and 2.13 $\mathrm{Mg} \cdot$ ha.year ${ }^{-1}$, respectively, are in the same order of magnitude as those estimated for Oliveros. The stable $\mathrm{C}$ content would represent $60 \%$ of the total $\mathrm{C}$ in the starting situation, i.e. a $\mathrm{C}$ content of

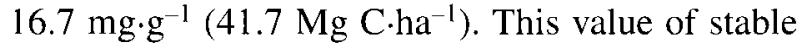
$\mathrm{C}$ represents the upper limit of all possible values

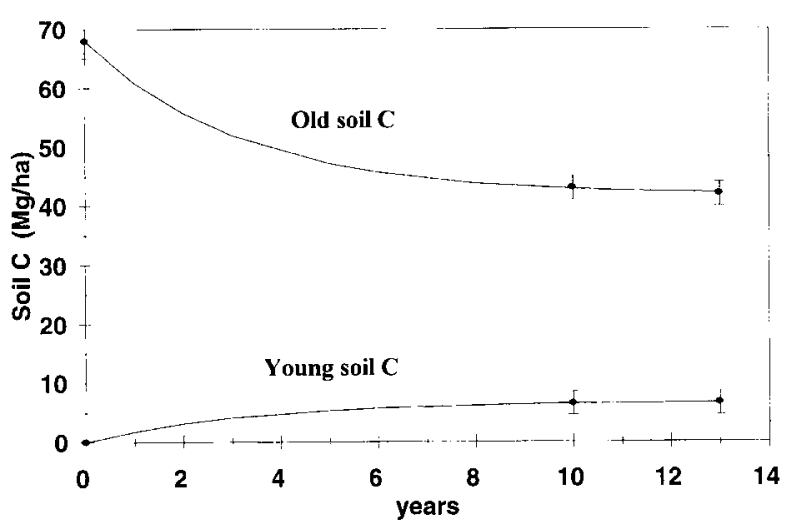

Figure 8. Evolution of predicted and observed old and young $C$ fractions of SOM under continuous soybean at Pergamino.

since this is a situation in which crops have just recently been introduced.

To be able to compare the results from Oliveros calculated for the $A_{p}$ horizon and those of Pergamino calculated on the basis of $2500 \mathrm{Mg}$. $\mathrm{ha}^{-1}$ of soil, the results were used for young and old $\mathrm{C}$ for years 8 and 9 of the w/s and w/s-f rotations and for year 8 of the maize monoculture. The estimated values, for an average mass of equivalent soil (2 $400 \mathrm{Mg} \cdot \mathrm{ha}^{-1}$ ), are shown in table $\mathrm{V}$. Assuming that after 8 or 9 years the rotations are almost in equilibrium, one may assume that the stable $\mathrm{C}$ content corresponds to the old $\mathrm{C}$ reserve,

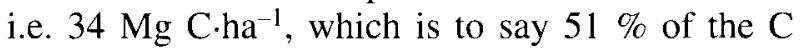
reserve in the virgin soil at Oliveros. This value agrees with that obtained with the CENTURY model by Anderson and Coleman [1] for a Montana Argiborol (USA). Similarly, for the Sanborn plots in the USA, Balesdent et al. [6] estimated, using the ${ }^{13} \mathrm{C}$ method, that the proportion of $\mathrm{C}$ coming from the original grassland is about $49 \%$ of the total $\mathrm{C}$ after 100 years of wheat monoculture.

\section{Conclusions}

The evolution of the SOM can be described, in the medium term, by a model with three compart- 
Table V. Old $\left(C_{1}\right)$ and young $\left(C_{2}\right)$ soil carbon contents estimated for three cropping sequences at Oliveros, measured in the $0-20 \mathrm{~cm}$ soil layer after 8 or 9 years.

\begin{tabular}{|c|c|c|c|c|c|c|c|}
\hline Crop sequence & $\begin{array}{c}\text { Year } \\
\left(\mathrm{mg} \cdot \mathrm{g}^{-1}\right)\end{array}$ & $\begin{array}{c}C_{1} \\
\left(\mathrm{mg} \cdot \mathrm{g}^{-1}\right)\end{array}$ & $\begin{array}{c}C_{2} \\
\left(\mathrm{Mg}^{-h^{-1}}\right)\end{array}$ & $\begin{array}{l}\text { Soil mass } \\
\left(\mathrm{Mg} \mathrm{ha}^{-1}\right)\end{array}$ & $\begin{array}{c}C_{1} \\
\left(\mathrm{Mg} \cdot \mathrm{ha}^{-1}\right)\end{array}$ & $\begin{array}{c}C_{2} \\
\left(\mathrm{Mg} \cdot \mathrm{ha}^{-1}\right)\end{array}$ & $C$ \\
\hline $\mathrm{m}$ & 8 & 13.6 & 18.9 & 2320 & 30.8 & 7.2 & 38.0 \\
\hline \multirow[t]{2}{*}{$\mathrm{w} / \mathrm{s}$} & 8 & 13.7 & 16.7 & 2460 & 33.8 & 6.8 & 40.6 \\
\hline & 9 & 13.4 & 17.8 & 2460 & 33.0 & 7.1 & 40.1 \\
\hline \multirow[t]{2}{*}{$w / s-f$} & 8 & 13.9 & 12.5 & 2360 & 32.8 & 4.7 & 37.5 \\
\hline & 9 & 13.0 & 12.5 & 2360 & 30.8 & 4.4 & 35.2 \\
\hline
\end{tabular}

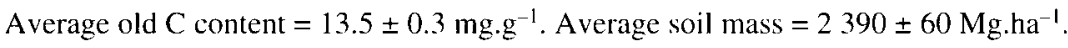

ments defined by their origin: the carbon from crop residues, the carbon of recent origin or young carbon, and the old or stable carbon. The ${ }^{13} \mathrm{C}$ method provides estimates of the size of each fraction and enables their changes to be followed. The three parameters $k_{1}, k$ and $C_{\mathrm{S}}$ can be precisely measured. At Oliveros, the size of the stable fraction $\left(C_{S}\right)$ would represent $51 \%$ of the soil $\mathrm{C}$ content under original grassland. After 70-80 years of cropping, the size of the active fraction $\left(C_{\mathrm{A}}\right)$ would represent on average $22 \%$ of the total $\mathrm{C}$ content, and its renewal time would vary from 3 to 6 years.

From the four rotations studied at Oliveros, it was shown that the humification yields $\left(k_{1}\right)$ depend on the nature of the harvest residues and vary in proportion to their lignin content. Moreover, it was observed that intensification of soil tillage caused by the practice of double cropping in a single year (wheat/soybean) is accompanied by a greater mineralisation of carbon, corresponding in the model to a substantial increase in the rate constant $k$. These two results deserve checking for their stability and the possibility of being extrapolated to other soil and climatic conditions and to other crops.

Such a model enables cropping systems favourable to the maintenance of the organic status of cultivated soils to be tested and proposed over the medium term. The application of such a model in the long term will require more investigations on the nature of the stable fraction and on the validity of estimates of its size.
Acknowledgements: This work was based on experiments set up by the Instituto Nacional de Tecnologia Agropecuaria at the Oliveros and Pergamino experimental stations. We thank the scientists and technicians who were kind enough to share their soil samples, crop yield data and knowledge of the rolling pampas with us. We also thank Dr Alan Scaife for the English revision of this paper. This work was possible owing to a contract of collaboration between Inra and INTA.

\section{References}

[1] Anderson D.W., Coleman C., The dynamics of organic matter in grassland soils, J. Soil Water Conserv. 40 (1985) 211-216.

[2]Andrén O., Kätterer T., ICBM. The introductory carbon balance model for exploration of soil carbon balances, Ecol. Appl. 7 (1997) 1226-1236.

[3] Andreux F., Bruckert S., Correa A., Souchier B., Sur une méthode de fractionnement physique et chimique des agrégats des sols: origines possibles de la matière organique des fractions obtenues, C. R. Acad. Sci. Paris 291D (1980) 381-384.

[4] Andreux F., Correa A., Caractères généraux de la matière organique de sols eutrophes et mésotrophes affectés ou non par des migrations particulaires, C. R. Coll. Int. CNRS $\mathrm{n}^{\circ} 303$, Migrations organo-minérales dans les sols tempérés, Nancy, 1981, pp. 329-339.

[5] Andriulo A., Mary B., Guérif J., Evolution of soil carbon in various cropping sequences of the rolling pampa. Determination of carbon origin using variations of natural ${ }^{13} \mathrm{C}$ abundance, Agronomie 19 (1999), 349-364. 
[6] Balesdent J., Wagner G.H., Mariotti A., Soil organic matter turnover in long-term field experiments as revealed by carbon-13 natural abundance, Soil Sci. Soc. Am. J. 52 (1988) 118-124.

[7] Balesdent J., Girardin C., Grably M., Guillemot J., Mariotti A., Petraud J.P., Picot C., Réponse des matières organiques des sols aux changements atmosphériques globaux: I. Compartimentation du carbone organique des sols cultivés, in: Ecosystèmes naturels et cultivés et changements globaux, Dourdan, InraDPE/CNRS-PIR, 1994, pp. 12-14.

[8] Bartoli F., Le cycle biogéochimique du silicium sur roche acide: application à deux écosystèmes forestières tempérés (Vosges), thèse, Univ. Nancy, 1981, $220 \mathrm{p}$.

[9] Boiffin J., Zaghabi J, Sebillote M., Systèmes de culture et statut organique des sols dans le Noyonnais: application du modèle de Hénin-Dupuis, Agronomie 6 (1986) 437-446.

[10] Bradbury N., Whitmore A.P., Hart P.B.S., Jenkinson D.S., Modelling the fate of nitrogen in crop and soil in the years following application of ${ }^{15} \mathrm{~N}$ labelled fertilizer to winter wheat, J Agric. Sci., Cambridge 121 (1993) 363-379.

[11] Chadoeuf J., Guérif J., Monnier G., Modélisation de l'évolution des matières organiques du sol, C. R. Contrat CEE-Inra n ${ }^{\circ}$ ESE-R-014 F, 1984.

[12] Djakovitch J.L., Mise au point d'une méthode de détermination rapide du coefficient isohumique de matériaux organiques utilisables pour l'amendement des sols, thèse CNAM, Bordeaux, 1988, 208 p.

[13] Guérif J., Modification de la répartition et de l'évolution des matières organiques par la simplification du travail du sol: conséquences sur quelques propriétés physiques, in: Les rotations céréalières intensives. Dix années d'études concertées, Inra-ONIC-ITCF, 1973-1983, Paris, 1986, pp. 63-88.

[14] Hénin S., Dupuis M., Essai de bilan de la matière organique du sol, Ann. Agron. 11 (1945) 17-29.

[15] Huggins D.R., Clapp C.E., Allmaras R.R., Lamb J.A., Layese M.F., Carbon dynamics in corn-soybean sequences as estimated from natural carbon-13 abundance, Soil Sci. Soc. Am. J. 62 (1998) 195-203.

[16] Janssen B.H., A simple method for calculating decomposition and accumulation of "young" organic matter, Plant Soil 76 (1984) 597-304.
[17] Jenkinson D.S, Rayner J.H., The turnover of soil organic matter in some of the Rothamsted classical experiments, Soil Sci. 123 (1977) 298-305.

[18] Jenkinson D.S., The turnover of soil organic carbon and nitrogen in soil, Phil. Trans. R. Soc. Lond. B (1990) 361-368.

[19] Linères M., Muller J.C., Remy J.C., Étude de la décomposition des pailles et des tiges de maïs, C. R. Contrat CEE-Inra, ESE-R-014 F, 1984.

[20] Mary B., Guérif J., Intérêts et limites des modèles de prévision de l'évolution des matières organiques et de l'azote dans le sol, Cah. Agric. 3 (1994) 247-257.

[21] Mc Gill W.B., Hunt H.W., Woodmansee R.G., Reuss J.O., PHOENIX, a model of the dynamics of carbon and nitrogen in grassland soils, Ecol. Bull. 33 (1981) 49-115.

[22] Neyroud J.A., Supcik P., Magnollay F., La part du sol dans la production intégrée. 1. gestion de la matière organique et bilan humique, Rev. Suisse Agric. 29 (1997) 45-51.

[23] Parton W.J., Schimel D.S., Cole C.V., Ojima D.S., Analysis of factors controling soil organic matter levels in great plains grasslands, Soil Sci. Soc. Am. J. 51 (1987) 1173-1179.

[24] Paustian K., Ågren G.I., Bosatta E., Modelling litter quality effects on decomposition and soil organic matter dynamics, in: Cadisch G., Giller K.E. (Eds.), Driven by Nature: Plant Litter Quality and Decomposition, CAB International, 1997, pp. 313-335

[25] Plénet D., Lubet E., Juste C., Evolution à long terme du statut carboné du sol en monoculture non irriguée du maïs (Zea mays L), Agronomie 13 (1993) $685-698$.

[26] Smith P., Powlson D.S., Smith J.U., Elliott E.T., Evaluation and comparison of soil organic matter models using datasets from seven long-term experiments, Geoderma 81 (1997).

[27] Van Veen J.A., Paul E.A., Organic carbon dynamics in grassland soils. I. Background information and computer simulation, Can. J. Soil Sci. 61 (1981) 185-201.

[28] Whitmore A.P., A method for assesing the goodness of computer simulation of soil processes, J. Soil Sci. 42 (1991) 289-299. 